\title{
Kenneth Ch'en, Histoire du bouddhisme en Chine
}

Traduit de l'anglais par Dominique Kych. Postface de Sylvie

Hureau.Paris, Les Belles Lettres, 2015, 592 p., index. Bibliographie.

\section{Benoît Vermander}

\section{(2) OpenEdition}

1 Journals

\section{Édition électronique}

URL : http://journals.openedition.org/assr/28207

DOI : 10.4000 /assr.28207

ISSN : $1777-5825$

Éditeur

Éditions de l'EHESS

\section{Édition imprimée}

Date de publication : 31 décembre 2016

Pagination : 292

ISSN : 0335-5985

\section{Référence électronique}

Benoît Vermander, « Kenneth Ch'en, Histoire du bouddhisme en Chine », Archives de sciences sociales des religions [En ligne], 176 | octobre-décembre 2016, mis en ligne le 17 juillet 2017, consulté le 24 septembre 2020. URL : http://journals.openedition.org/assr/28207; DOI : https://doi.org/10.4000/ assr.28207

Ce document a été généré automatiquement le 24 septembre 2020.

(c) Archives de sciences sociales des religions 


\section{Kenneth Ch'en, Histoire du bouddhisme en Chine}

Traduit de l'anglais par Dominique Kych. Postface de Sylvie Hureau.Paris, Les Belles Lettres, 2015, 592 p., index. Bibliographie.

\section{Benoît Vermander}

\section{RÉFÉRENCE}

Kenneth Ch'en, Histoire du bouddhisme en Chine, Traduit de l'anglais par Dominique Kych, Postface de Sylvie Hureau, Paris, Les Belles Lettres, 2015, 592 p., index, Bibliographie

1 Ce livre est la traduction d'un ouvrage de référence sur le bouddhisme chinois paru en 1964. Le travail de traduction réalisé est excellent, très soigné, avec retour aux textes chinois cités, et un utile lexique des noms et titres chinois. L'ouvrage lui-même est de facture très classique, présentant une histoire ordonnée par dynasties avec chapitres complémentaires sur la doctrine, la traduction du Canon bouddhiste, les temples, ou les moines éminents. L'auteur est particulièrement à son aise dans les résumés doctrinaux et la présentation des textes canoniques, mais on trouvera là d'excellentes synthèses sur bien d'autres sujets, par exemple sur l'organisation et l'économie des grands monastères.

2 Près de 380 pages sont consacrés à la naissance, l'arrivée en Chine, la croissance et l'apogée du bouddhisme, avant que la période du « déclin » commence avec les Song une ligne narrative poursuivie presque inexorablement. Les dynasties Ming et Qing sont traitées très rapidement, et la description donnée de l'aggiornamento bouddhiste de la période qui suit l'écrasement de la rébellion Taiping jusqu'à l'établissement de la République populaire de Chine - est clairement insuffisante. La date de publication de la version originale de l'ouvrage explique le ton très sombre des dernières pages (même si l'auteur semble parier en finale sur la résilience et la capacité d'adaptation du 
bouddhisme chinois, pari que les évolutions intervenues après 1980 ont justifié au-delà de ses espérances).

3 La publication en français d'une pareille synthèse est en soi une excellente nouvelle, même si l'on se demande un peu quel est le public visé. Pédagogique et de lecture aisée, l'ouvrage reste d'écriture assez conventionnelle, parfois monotone, si bien qu'il ne s'agit sans doute pas d'une synthèse idéale pour le grand public cultivé, auquel on recommanderait de préférence des ouvrages plus courts et plus vivants portant sur tel ou tel aspect du sujet couvert. En revanche, étudiants en histoire chinoise ou en sciences religieuses trouveront là un ouvrage de consultation fiable et commode, qui pourra orienter leurs lectures ultérieures. Le rôle de consultation et d'orientation joué par l'ouvrage est encore renforcé par l'excellente bibliographie critique rédigée par l'auteur, comme par la bibliographie additionnelle établie par Sylvie Hureau. Cette dernière annexe est extrêmement complète, très à jour, et ajoute grandement à l'intérêt de la publication.

4 Dans l'idéal, la bibliographie additionnelle aurait pu être accompagnée d'une synthèse relatant les principales évolutions intervenues dans l'approche de l'histoire du bouddhisme chinois depuis la publication de l'ouvrage. Elles sont nombreuses, qu'il s'agisse de l'écriture de l'histoire de l'école chan, de la relation entre bouddhisme et religion populaire, des origines et de l'affirmation du «bouddhisme humaniste », ou des codes rhétoriques gouvernant les écrits hagiographiques. Le livre de Kenneth Ch'en a marqué un moment de la connaissance, et une évaluation historiographique d'ensemble aurait donné une valeur accrue et un horizon critique aux additions bibliographiques. Par ailleurs, puisque ce sont plus de cinquante ans de l'histoire du bouddhisme chinois qui ne sont pas couverts par l'ouvrage (davantage en fait, toute la partie consacrée à l'après 1949 n'étant guère utilisable), une courte synthèse sur cette période, et notamment sur le renouveau en cours, aurait également été bienvenue. Il est vrai que, tel quel, l'ouvrage est déjà fort volumineux et qu'il constitue une ressource des plus appréciables malgré son caractère quelque peu daté. 